\title{
Review of Alzheimer's disease scales: is there a need for a new multi-domain scale for therapy evaluation in medical practice?
}

\author{
Philippe Robert ${ }^{1 *}$, Steven Ferris ${ }^{2}$, Serge Gauthier ${ }^{3}$, Ralf $\mathrm{Ihl}^{4}$, Bengt Winblad ${ }^{5}$, Frank Tennigkeit ${ }^{6}$
}

\begin{abstract}
Introduction: The present review of Alzheimer's disease (AD) rating scales aims to outline the need for a new rating scale to be used in routine clinical practice for long-term medical care of AD patients. An ideal scale would be: 1) practical, easy and quick to administer for an experienced clinician; 2) validated for AD; 3) multi-domain: covering the AD-relevant areas of cognition, activities of daily living, behavior, communication/social interaction, and quality of life; 4) applicable to all AD severity stages; 5) able to monitor disease progression; and 6) sensitive to measure therapy effects.
\end{abstract}

Methods: The National Library of Medicines' MEDLINE database was searched for the years 1981 to September 2008, using a set of keywords aiming to select instruments which cover at least some of the requirements for an ideal practical AD scale for therapy evaluation. Measures for AD staging and screening tests were not considered for review.

Results: Of 1,902 articles resulting from the literature search, 68 relevant AD scales were identified. Most of them were scales that predominantly measure the severity of major dysfunctions in particular AD domains. Only five scales met some of the requirements for a practical multi-domain AD scale, but did not possess all required characteristics.

Conclusions: Despite the multitude of AD scales for various purposes, there remains a need for a new multidomain and easy to administer AD scale for assessment of disease progression and response to therapy in daily medical practice.

\section{Introduction}

Alzheimer's disease (AD), together with other forms of dementia, represents a major challenge for health care systems with aging populations. AD is associated with neurodegenerative changes which compromise not only cognitive functioning but also lead to a decline in functional abilities and induce a spectrum of psychological or behavioral symptoms [1]. Many efforts are currently undertaken to investigate AD pathology and develop appropriate treatment strategies. These strategies focus on long-term preservation of cognitive and functional abilities or slowing down disease progression along with reducing behavioral symptoms and maintaining the

\footnotetext{
* Correspondence: phil.robert15@orange.fr

'Memory Center, CHU - University of Nice Sophia Antipolis, Hôpital de

Cimiez, 4 av Victoria, 06000 Nice, France

Full list of author information is available at the end of the article
}

patient's quality of life $[2,3]$. As long as there is no treatment leading to reversal or stopping of disease progression, an amelioration of the disease symptoms, which may delay institutionalization, as well as a reduction of caregiver burden and costs, are realistic treatment goals today.

Rating scales are essential tools for AD diagnosis, staging, assessment and careful monitoring of AD symptoms as well as for evaluation of treatment effects. For decades most $\mathrm{AD}$ assessments were predominantly focused on cognition, which is the lead symptom in AD. Nevertheless, it has been realized that the symptoms more relevant to a patient's quality of life, caregiver burden and institutionalization are functional and behavioral symptoms [4]. In the $1990 \mathrm{~s}$, the development of new measures was requested by regulatory authorities to demonstrate clinically relevant treatment effects on 
cognition, daily functioning, and global changes. Presently, rating scales for assessment of both behavior and functioning, besides cognition, and evaluation of a patient's global impression are standard outcome measures in AD clinical trials [5]. Also, scales for assessment of advanced AD patients have been developed [6,7], demonstrating the considerably retained abilities of such patients and refuting the belief that patients beyond the moderate stage are not accessible to pharmacological and non-pharmacological treatment. Nevertheless, a need for better instruments, which are more sensitive to disease staging or changes over time, has been acknowledged by the European Medicines Agency [5] and recently confirmed by reviewing the outcome measures used in current clinical trials [8].

Despite the extensive development of rating scales for $\mathrm{AD}$ research, the overall assessment of disease progression in routine medical practice remains lengthy and complicated. One reason for that is the need for using a set of scales to assess all AD-relevant symptom domains, which is usually an arduous procedure for both physician and patient/caregiver. Also, most rating scales are not applicable to all $\mathrm{AD}$ severity stages, that is, many assessment tools are not consistently sensitive to measure disease progression or therapy effects across the whole patient population.

To discuss the use of current rating scales for evaluation of AD therapy in AD daily medical practice, an expert panel group composed of the authors of this article was set up (14 and 15 September 2007). The panel assumed that an ideal AD instrument for daily medical practice should cover all requirements presented in Table 1.

In this paper, we provide a brief overview on $\mathrm{AD}$ scales developed for assessment of cognition, daily function, global impression, behavior, quality of life as well as communication and social interaction, with a focus on their applicability in daily medical practice for monitoring disease progression and therapy effects. The review does not pretend to have included all scales available and used in $A D$ clinical practice so far. It rather summarizes individual scales for the various $\mathrm{AD}$ symptom domains and points to the need for a new multi-domain AD scale to enable disease assessment over time in daily medical practice.

\section{Materials and methods}

To discover available AD scales covering the requirements listed in Table 1, we performed a systematic literature search, employing the National Library of Medicines' MEDLINE database. For this purpose, an appropriate search algorithm was established: i) to ensure the inclusion of records about tools used in the assessment of AD (keywords: Alzheimer ('s disease), scale, assessment, rating/rater, questionnaire); ii) to avoid the inclusion of records about measures only for AD diagnosis and staging (keywords: efficacy, outcome, disease progression); iii) to include records on aspects considered neglected in many AD scales (keywords: quality of life, communication, social interaction/activities). Only documents in English, French, German, Italian, and Spanish were considered. Measures specialized on specific topics (for example, assessment of visuospatial functioning, verbal learning) or not developed for $\mathrm{AD}$, dementia, or geriatric patients were omitted. Computerized instruments were not considered due to the technical demands often deemed incompatible with daily practice use. Caregiver burden tools were also excluded since only scales for assessment of AD symptoms were of interest for this literature review.

Two independent reviewers assessed each selected article independently and with regard to its suitability and quality. In cases when the reviewers could determine from the abstract that the selection criteria were not met, the respective articles were rejected; or when a paper could not be rejected with certainty from the abstract, the full text article was obtained and evaluated. In addition, the references included in the selected articles were evaluated to identify further possible documents of interest. Any differences between the reviewers' results were resolved by discussion.

Each rating scale identified from the selected articles was compared with the requirements for a multi-domain $\mathrm{AD}$ scale for daily medical practice given in Table 1 .

\section{Results and discussion}

Our systematic literature search revealed a total of 1,902 articles published from July 1981 to September 2008. By screening the results, special attention was paid to identification of scales containing items of several AD symptom domains, excluding instruments mainly used for

\section{Table 1 Characteristics of a multi-domain AD scale for daily medical practice}

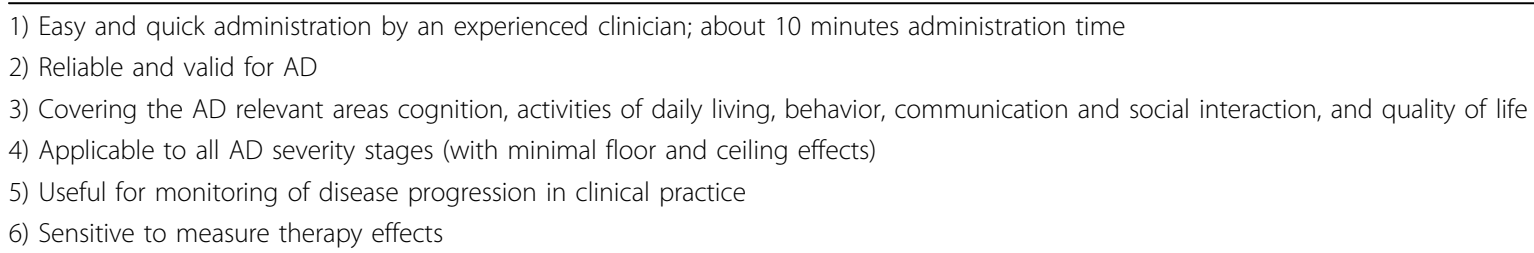


AD diagnosis and staging or screening tests. Reviews, editorials, meta-analyses, or studies published in English, French, German, Italian, and Spanish languages were considered. Most of the selected articles referred to validated and AD-specific tools developed over the last three decades to assess the regulatory relevant ADsymptom complexes: cognition, activities of daily living (ADL), and global changes. The rest of the articles revealed instruments for assessment of behavior, patient's quality of life, and communication and social interaction. Out of all selected articles, 68 relevant AD scales were identified. An overview of the scales grouped by AD symptom domains is provided in Table 2 .

\section{Cognition}

A total of nine instruments for assessment of cognitive impairment were identified by the literature search (Table 2). They comprise measures of cognition in patients with mild to severe $\mathrm{AD}$, which have been used in different clinical settings. The most often used scale for assessment of cognition is the Mini-Mental State Examination (MMSE). It was designed as a practical tool for grading the cognitive state of patients [9]. The target population is patients with cognitive disturbances derived from dementia syndromes, affective or personality disorders. The scale comprises 11 questions or simple tasks concerning orientation, memory, attention and language to evaluate the patient's cognitive state. Other mental or behavioral aspects are excluded, thus it requires only 5 to 10 minutes for a trained rater to administer it. The MMSE is the standard staging and assessment tool in AD. Given the widespread use of the MMSE, clinical and research findings can be easily compared. However, there are several drawbacks limiting the utility of MMSE. Some items are judged to be relatively easy and therefore patients with mild AD are not sensitively evaluated due to ceiling effects [10]. In contrast, floor effects limit the application to patients with more advanced AD. Furthermore, using MMSE for staging of $\mathrm{AD}$ severity neglects other more patient- and caregiverrelevant domains of $\mathrm{AD}$ assessment, such as function and behavior. Also, measurement error, practice effect, or other factors such as age, education or cultural background may impair the sensitivity and validity of the assessment of disease progression and pharmacological treatment effects [11-13].

Another scale used in almost all clinical trials on symptomatic AD therapy is the Alzheimer's Disease Assessment Scale (ADAS). It was designed to assess both cognitive and non-cognitive $\mathrm{AD}$-specific symptoms [14]. The cognitive subscale, ADAS-Cog, is a standard tool in pivotal clinical trials to detect therapeutic efficacy in cognition. It consists of 11 subtests related to memory, praxis, and language. The non-cognitive subscale of
ADAS comprises 10 items evaluating mood and behavioral changes. Depending on the AD severity stage of a patient, the administration of ADAS-Cog takes 30 to 45 minutes. In contrast to the ADAS-Cog, the non-cognitive subscale is rarely used. The ADAS-Cog appears to be most adequate for patients with moderate AD. Patients with mild cognitive impairment and mild AD are subject to ceiling effects and patients in advanced AD stage are subject to floor effects, in part due to eroding language abilities. In general, the measurement error of ADAS-Cog limits disease progression monitoring, especially in short-term evaluations [15]. As the original ADAS-Cog neglects some cognitive functions, such as planning and executive function, several additional subtests have further been developed [16].

As the standard cognitive tools MMSE and ADASCog are not considered sensitive enough to measure treatment effects in early disease stages optimally, a Neuropsychological Test Battery (NTB) has recently been developed to fill this gap [17]. The NTB is designed to emphasize the assessment of memory and executive function in patients with mild to moderate $\mathrm{AD}$, combining nine previously validated cognitive tests. In addition, it provides an index of global cognitive function in mild AD patients. The completion of the NTB takes about 40 minutes.

To enable the assessment of cognition in later $\mathrm{AD}$ stages, the Severe Impairment Battery (SIB) was developed $[6,18]$. The SIB, rather than rating erroneous performance, relies on the appraisal of preserved abilities in nine cognitive domains: social interaction, memory, orientation, language, attention, praxis, visuospatial abilities, constructional abilities and orientation to name. A maximum of 30 minutes is required for administration. A short SIB version [19] and a version based on the SIB-language domain, SIB-L [20], have also been developed. Another brief, reliable and valid measure of cognitive function in severely demented AD patients is the Severe Cognitive Impairment Rating Scale [21]. For staging the severity of cognitive deficits and assessing the benefits of AD therapy, the Syndrom-Kurztest [22] has extensively been used in earlier clinical trials. It is well accepted by patients, hospital clinicians, and general practitioners due to its brevity and simplicity.

\section{Activities of daily living (ADL)}

Among numerous ADL scales available for several decades to rate the degree of disability or the need for assistance in geriatric population, 17 ADL instruments were identified by the literature search presented here (Table 2). In general, basic ADL, including self-maintenance skills such as walking, feeding, and dressing, are distinguished from the instrumental activities of daily living (IADL), addressing more complex activities such 
Table 2 Identified instruments for assessment of AD symptoms

\begin{tabular}{|c|c|c|c|}
\hline $\begin{array}{l}\text { Aspects of } A D \\
\text { disorder }\end{array}$ & Abbreviation & Full name & \\
\hline \multirow{9}{*}{$\begin{array}{l}\text { Cognitive } \\
\text { Impairment }\end{array}$} & ADAS-Cog & Alzheimer's Disease Assessment Scale - Cognitive Subscale [14] & Rosen et al.1984 \\
\hline & BIMC & Blessed Information-Memory-Concentration Test [77] & Blessed et al. 1968 \\
\hline & CAMCOG & Cambridge Cognitive Examination [78] & Grevett \& O'Brien 2002 \\
\hline & MDRS & Mattis Dementia Rating Scale [79] & Mattis 1976 \\
\hline & MMSE & Mini-Mental State Examination [9] & Folstein et al. 1975 \\
\hline & NTB & Neuropsychological Test Battery [17] & Harrison et al. 2007 \\
\hline & SCIP & Severe Cognitive Impairment Profile [21] & Peavy et al. 1996 \\
\hline & $\mathrm{SIB}$ & Severe Impairment Battery [6] & Saxton \& Swihart 1989 \\
\hline & SKT & Syndrom-Kurztest [22] & Erzigkeit 1989 \\
\hline \multirow{17}{*}{$\begin{array}{l}\text { Activities of Daily } \\
\text { Living }\end{array}$} & ADL-PI & Activities of Daily Living-Prevention Instrument [31] & Galasko et al. 2006 \\
\hline & ADLQ & Activities of Daily Living Questionnaire [80] & Johnson et al. 2004 \\
\hline & $\begin{array}{l}\mathrm{ADCS}_{23}-\mathrm{ADL}_{19 /} \\
\end{array}$ & $\begin{array}{l}\text { Alzheimer's Disease Cooperative Study Activities of Daily Living Inventory 19- or } \\
\text { 23-item Scale [25] }\end{array}$ & Galasko et al. 1997 \\
\hline & B-ADL & Bayer Activities of Daily Living Scale [30] & Hindmarch et al. 1998 \\
\hline & Bristol ADL & Bristol Activities of Daily Living Scale [81] & Bucks et al. 1996 \\
\hline & BANS-S & Bedfords Alzheimer's Nursing Severity Scale [82] & Bellelli et al. 1997 \\
\hline & Barthel ADL & Barthel Activities of Daily Living Index Scale [83] & Mahoney \& Barthel 1965 \\
\hline & DAD & Disability Assessment for Dementia [26] & Gelinas et al. 1999 \\
\hline & GERRI & Geriatric Evaluation by Relative's Rating Instrument [84] & Schwartz 1983 \\
\hline & IADL & Instrumental Activities of Daily Living Scale [24] & Lawton \& Brody 1969 \\
\hline & IDDD & Interview for Deterioration in Daily Living Activities in Dementia [27] & Teunisse et al. 1991 \\
\hline & Katz ADL & The Katz Index of Independence in Activities of Daily Living [23] & Katz et al. 1963 \\
\hline & PGDRS & Psychogeriatric Dependency Rating Scales [85] & $\begin{array}{l}\text { Wilkinson \& Graham- } \\
\text { White } 1980\end{array}$ \\
\hline & RDRS & Rapid Disability Rating Scale [29] & Linn 1976 \\
\hline & PSMS & Physical Self-Maintenance Scale [24] & Lawton \& Brody 1969 \\
\hline & SMAF & Functional Autonomy Measurement System [28] & Hebert et al. 2001 \\
\hline & $\begin{array}{l}\text { Weintraub } \\
\text { ADL }\end{array}$ & Weintraub Activities of Daily Living Scale [86] & Weintraub 1986 \\
\hline \multirow[t]{8}{*}{ Global Impression } & ADCS-CGIC & Alzheimers' Disease Cooperative Study - Clinical Global Impression of Change [38] & Schneider et al. 1997 \\
\hline & CDR & Clinical Dementia Rating Scale [35] & Hughes et al. 1982 \\
\hline & CGl & Clinical Global Impression [34] & Guy 1976 \\
\hline & $\mathrm{C}|\mathrm{B}|$ & Clinical Interview Based Impression (Parke-Davis) [87] & Knopman et al. 1994 \\
\hline & FAST & The Functional Assessment Staging [37] & Reisberg 1988 \\
\hline & GDS & Global Deterioration Scale [36] & Reisberg 1982 \\
\hline & HDR & Hierarchic Dementia Rating Scale [88] & Cole \& Dastoor 1983 \\
\hline & $\begin{array}{l}\text { NYU CIBIC- } \\
\text { Plus }\end{array}$ & $\begin{array}{l}\text { The New York University - Clinician's Interview-Based Impression of Change - Plus } \\
\text { Caregiver Input [39] }\end{array}$ & Reisberg \& Ferris 1994 \\
\hline \multirow{10}{*}{$\begin{array}{l}\text { Behavior/ } \\
\text { Neuropsychology }\end{array}$} & AMS & Alzheimer's Mood Scale [52] & Tappen \& Williams 1999 \\
\hline & IA & Apathy Inventory [49] & Robert et al. 2002 \\
\hline & BEAM-D & Behavioral and Emotional Activities Manifested in Dementia [89] & Sihna et al. 1992 \\
\hline & BEHAVE-AD & Behavioral Pathology in Alzheimer's Disease Rating Scale [40] & Reisberg et al. 1987 \\
\hline & BPRS & Brief Psychiatric Rating Scale [41] & Overall \& Gorham 1962 \\
\hline & CERAD-BRSD & $\begin{array}{l}\text { Behavior Rating Scale for Dementia of the Consortium to Establish a Registry for } \\
\text { Alzheimer's Disease [45] }\end{array}$ & Tariot et al. 1995 \\
\hline & CMAI & Cohen-Mansfield Agitation Inventory [47] & Cohen-Mansfield 1986 \\
\hline & CSDD & Cornell Scale for Depression in Dementia [51] & Alexopoulos et al. 1988 \\
\hline & DBD & Dementia Behavior Disturbance Scale [46] & Baumgarten et al. 1990 \\
\hline & DMAS & Dementia Mood Assessment Scale [50] & Sunderland et al. 1988 \\
\hline
\end{tabular}


Table 2 Identified instruments for assessment of AD symptoms (Continued)

\begin{tabular}{|c|c|c|c|}
\hline & GDS & Geriatric Depression Scale [48] & Yesavage et al. 1983 \\
\hline & HONOS $65+$ & Health of the Nation Outcome Scale for Elderly People [90] & Burns et al. 1999 \\
\hline & NPI & Neuropsychiatric Inventory [42] & Cummings et al. 1994 \\
\hline & NRS & Neurobehavioral Rating Scale [91] & Sultzer et al. 1995 \\
\hline & RMBPC & Revised Memory and Behavior Problems Checklist [92] & Teri et al. 1992 \\
\hline \multirow[t]{7}{*}{ Quality of Life } & ADRQL & Alzheimer Disease Related Quality of Life [57] & Rabins et al. 1999 \\
\hline & DQoL & Dementia Quality of Life Instrument [58] & Brod et al. 1999 \\
\hline & DS-DAT & Discomfort Scale for Dementia of Alzheimer's Type [64] & Hurley et al. 1992 \\
\hline & OERS & Observed Emotion Rating Scale [93] & Lawton et al. 1999 \\
\hline & PDS & Progressive Deterioration Scale [62] & DeJong et al. 1989 \\
\hline & QoL-AD & Quality of Life-Alzheimer's Disease $[59,60]$ & Logsdon et al. 1999 \\
\hline & QUALID & Quality of Life in Late-Stage Dementia Scale [61] & Weiner et al. 2000 \\
\hline $\begin{array}{l}\text { Communication/ } \\
\text { Social }\end{array}$ & CLB & Core Linguistic Battery [94] & Bayles et al. 1992 \\
\hline \multirow[t]{6}{*}{ Interaction } & CPS & Communication Problems Scale [66] & Powell et al. 1995 \\
\hline & ERT & Emotion Recognition Test [95] & Shimokawa et al. 2000 \\
\hline & MOSES & Multidimensional Observation Scale for Elderly Subjects [96] & Helmes et al. 1987 \\
\hline & PKT & Posture Knowledge Test [97] & Mozaz et al. 2002 \\
\hline & PPQSA & Partner-Patient Questionnaire for Shared Activities [98] & Reilly 2006 \\
\hline & SCS & Social Competence Scale [99] & Zigler \& Phillips 1961 \\
\hline \multirow[t]{5}{*}{ Multi-domain } & BGP & Behavioral Rating Scale for Geriatric Patients [71] & van der Kam et al. 1971 \\
\hline & GBS & Gottfries-Brane-Steen Scale $[68,69]$ & Gottfries et al. 1982 \\
\hline & NOSGER & Nurses' Observation Scale for Geriatric Patients[70] & Brunner \& Spiegel 1990 \\
\hline & SCAG & Sandoz Clinical Assessment Geriatric Scale [67] & Shader et al. 1974 \\
\hline & $\mathrm{VL}$ & The Vienna List [72] & Porzsolt et al. 2004 \\
\hline
\end{tabular}

as shopping, cooking, handling finances, or using the telephone or transportation. The oldest and most widely used tools to assess functioning are the Katz Index of ADL, which covers six basic ADL (bathing, dressing, toileting, transfer, continence, feeding) [23], and the ADL/ IADL scales developed by Lawton and Brody (1969), which contain both basic ADL and IADL [24].

The Alzheimer's Disease Cooperative Study (ADCS) tested 45 ADL items for use in AD clinical trials and found 27 to be widely applicable for assessment of functional capacity across a wide spectrum of severity [25]. The 19-item version (ADCS-ADL 19 ), covering mainly basic ADL, is used for the assessment of patients with more severe AD, while the 23-item version (ADCS$\mathrm{ADL}_{23}$ ) includes more complex ADL for the assessment of mild to moderate $\mathrm{AD}$, such as reading books or magazines, pastime activities, or household chores. Ratings take about 20 minutes and are based on information obtained from the patient and caregiver. The scores range from 0 to 78 , higher scores indicating less functional impairment. Another AD-specific and commonly used scale for functional assessment is the Disability Assessment for Dementia [26]. Based on an interview with the caregiver, the clinician evaluates whether the patient needs support concerning initiation, organization and planning, and effective performance in 10 areas of functioning, including basic, instrumental, and leisure daily activities. Other functional instruments used in different clinical settings for assessment of AD patients are the Interview for Deterioration in Daily Living Activities in Dementia [27], the Functional Autonomy Measurement System [28], and the Rapid Disability Rating Scale [29]. The Bayer Activities of Daily Living Scale (B-ADL) was developed for patients with mild cognitive impairment or mild to moderate dementia to measure deficits in the performance of everyday activities [30]. It is a useful tool for evaluation of treatment effects and the progress of dementia in general practice primary care. Other functional instruments particularly used for patients with mild cognitive impairment are the Activities of Daily Living-Prevention Instrument [31], developed to rate ADL in prevention of dementia studies, and the Functional Assessment Questionnaire [32]. A recent review of the IADL scales has pointed to a need for an improvement in the psychometric properties of the currently available IADL instruments in order to justify better their usefulness in clinical practice [33].

\section{Global impression}

The concept of Clinical Global Impression (CGI) for evaluation of pharmacological treatment effects was introduced by Guy, 1976 [34]. The CGI scales rely on 
the clinician's rating of global severity and/or change in patient's clinical condition. Global measures developed for use in dementia are normally based on a comprehensive and (semi-) structured interview with the patient and other suitable (caregiver-) informants [13]. The scales characterize clinically manifested changes of dementia, based on a multidimensional evaluation of cognitive, functional, and behavioral symptoms. The global measures selected by our literature search (Table 2) include global severity scales, such as the Clinical Dementia Rating [35], the Global Deterioration Scale [36], and the Functional Assessment Staging [37], and global change scales, such as the Alzheimer's Disease Cooperative Study - Clinical Global Impression of Change [38] and the New York University - Clinician's Interview Based Impression of Change - Plus Caregiver Input [39]. The administration time of global assessment scales ranges from 5 to 45 minutes depending on the amount of information to be gathered. The main advantage of global measures is that they take into account multiple domains of real life information and, in contrast to performance-based tools such as MMSE, a detected change in the patient's condition is clinically meaningful, as an experienced clinician can detect the change. On the other hand, most global measures do not allow separate monitoring of changes over time in several AD-relevant domains.

\section{Behavior}

During the last decades, several instruments have been developed to assess behavioral and psychological symptoms in AD patients. Our literature search identified 15 scales, including instruments for assessment of behavior and mood. The BEHAVE-AD was developed to assess behavior in patients with $\mathrm{AD}$ apart of cognitive symptomatology [40]. It covers symptoms in seven categories: paranoid and delusional ideation, hallucinations, activity disturbances, diurnal rhythm disturbances, aggressiveness, affective disorders and anxieties, and phobias. The administration time is about 20 minutes, and behavior is rated as mild, moderate, or severe. An early developed instrument for assessment of behavior, which is still often used in clinical practice and psychopharmacological research, is the Brief Psychiatric Rating Scale (BPRS). It contains 18 items grouped in five factors - depression, agitation, cognitive dysfunction, hostile suspiciousness, and psychotic distortion - rated on a seven-point severity scale [41]. The administration of the BPRS takes 20 minutes by an experienced clinician and is based on observation of and self-reporting by the patient. Presently, the most widely used behavior scale in AD is the Neuropsychiatric Inventory (NPI). It was developed to compensate for shortcomings of the BEHAVE-AD, which neglects symptoms related to apathy, irritability, or disinhibition [42]. The NPI distinguishes between frequency and severity of symptoms; it is informant-based and requires about 30 minutes for administration. A brief version was developed, which relies on a questionnaire and assesses only symptom severity [43]. However, as the NPI contains contradicting opposing symptoms (euphoria and depression), the value of the NPI total score has recently been called into question [44] and it seems more important to look at the scoring of each behavioral domain.

Other instruments used in clinical settings for rating behavioral abnormalities in patients with $\mathrm{AD}$ are the Behavior Rating Scale for Dementia of the Consortium to Establish a Registry for Alzheimer's Disease [45], the Dementia Behavior Disturbance Scale [46], as well as instruments targeting specific behaviors, such as the Cohen-Mansfield Agitation Inventory [47] for agitation and aggressiveness, the Geriatric Depression Scale [48] for depression, and the Apathy Inventory [49]. In addition, there are instruments designed specifically for assessment of depression severity and mood changes in demented patients, such as the Dementia Mood Assessment Scale [50], the Cornell Scale for Depression in Dementia [51], and the Alzheimer's Mood Scale [52].

\section{Quality of life}

In the second half of the $1990 \mathrm{~s}$, following a general medical trend of moving away from mainly symptom treatment towards patient-centered medical care, the development of scales for assessment of quality of life (QoL) became a new challenge. Most dementia QoLscales refer to Lawton's model of QoL in dementia [53]. According to this model, QoL is the result of a dynamic interaction between four patient-relevant dimensions: psychological well being, perceived quality of life, behavior competence, and environment [54]. QoL scales contain aspects not considered in most conventional scales, such as interpersonal relationships, self-esteem, living environment, being useful, giving meaning to life, or financial situation. In general, QoL instruments are specific to the severity stage of AD and differ with regard to the domains covered. Most QoL scales are short and easy to administer. However, there has been substantial debate whether patients with $\mathrm{AD}$, especially in more advanced stages, can reliably report on their QoL and whether caregiver reports are an appropriate alternative [55]. Furthermore, the individual designation of QoL is rather flexible and inherently differing among people, which makes the common understanding of what is important for the QoL of a person with dementia a challenge for researchers and clinicians. To rate the extent to which treatment goals individually defined by the patient, caregiver or physicians are achieved, the method of 
goal attainment scaling was developed and applied to both geriatric and dementia populations [56].

Among the QoL scales selected in our search were the Alzheimer Disease Related Quality of Life (ADRQL) [57], the Dementia Quality of Life Instrument (DQoL) [58], the Quality of Life - Alzheimer's Disease (QoL-AD) [59,60], and the Quality of Life in Late-Stage Dementia Scale (QUALID) [61]. The ADRQL is an observer-rated instrument, which measures positive and negative behavior across five domains: social interaction, awareness of self, feelings and mood, enjoyment of activities, and response to surroundings. It is appropriate to use in daytime activities settings and is applicable to all stages of dementia. The DQoL instrument is a 29-item scale designed for assessment of QoL in mild to moderate demented patients. Ratings are based on an interview with the patients and give estimates for positive and negative affects, feelings of belonging, sense of aesthetics, and self-esteem. The QoL-AD was developed for both patients and caregivers to measure QoL in $A D$, and can be used for patients with MMSE score $>10$. It includes 13 items providing assessment of mood, physical health, memory, relationship, self-esteem, and current situation. Another QoL instrument specifically designed for AD patients is the Progressive Deterioration Scale [62]. It is relatively easy to administer, only 10 to 15 minutes to complete, and has been often used in clinical settings. In addition, the QoL measures include the Schedule for the Evaluation of Individual Quality of Life - Direct Weighing (SEIQoL-DW), a self-rating instrument which allows patients to designate and weigh the most important domains affecting their quality of life [63]. Another easy to use but requiring extensive training for administration instrument is the Discomfort Scale - Dementia of Alzheimer Type [64]. It is an observation assessment scale developed to measure discomfort in the elderly with AD.

\section{Communication and social interaction}

Improving QoL of $\mathrm{AD}$ patients requires specific instruments to assess problems related with the ability of patients to communicate and interact with others. Communication breakdown in $\mathrm{AD}$ results from disturbances in semantic and linguistic processes or memory deficits and causes a large number of symptoms. The diminished ability to communicate leads to a decline in the quality of social interactions and increased caregiver burden [65]. Our literature search revealed seven instruments for assessment of symptoms of communication breakdown. An example for evaluation of semantic and pragmatic problems in communication with AD patients is the Communication Problems Scale [66]. It is a 16item inventory administered to caregivers, who estimate the frequency of each communication behavior on a five-point score.

\section{Selected multi-domain scales}

In this study, the literature survey was based on predefined requirements for a multi-domain $\mathrm{AD}$ scale for therapy evaluation in daily medical practice in order to identify existing AD scales which might cover the criteria, respectively. Most of the selected scales (Table 2) appear to evaluate aspects which can be predominantly assigned to a single AD symptom domain, namely cognition, ADL, or behavior, including also a few scales selected as tools for assessment of patients' well-being, affects, apathy, mood, pain, and communication/social interaction. A number of global and QoL scales were also identified by the search. In general, conventional AD symptom domains can not be allocated to QoL scales. These assessment tools are inherently multidimensional, delivering a subjective patient perspective; however, they can not replace the detailed evaluation of function or behavior.

Besides these scales, our literature survey yielded only a few scales that allow assessment of several ADdomains (cognition, ADL, behavior, including also communication/social interaction) and cover at least some of the requirements for a multi-domain instrument for therapy evaluation in daily medical practice, listed in Table 1. The selected multi-domain scales are: the Sandoz Clinical Assessment Geriatric (SCAG) [67], the Gottfries-Brane-Steen (GBS) [68,69], the Nurses' Observation Scale for Geriatric Patients (NOSGER) [70], the Behavioral Rating Scale for Geriatric Patients (BGP) [71], and the Vienna List [72]. Table 3 provides a brief overview on the AD-domains covered by the scales, the patient population, scale administration and application.

The SCAG is a general-purpose rating scale to assess changes following treatment. It contains 18 items, comprising the assessment of agitation, cognitive dysfunction, depressed mood, and withdrawal, scored on a seven-point scale. An additional item, item 19 of the SCAG, is included for global severity rating. A skilled clinician administers the scale over 15 to 30 minutes. Rating is based on observed behavior and not on the patient's own impression. The SCAG was designed specifically for evaluation of pharmacotherapy in senile dementia and for a time was widely used as an outcome measure in drug research [73].

The GBS was designed to measure the degree of dementia and to profile dementia syndromes. It consists of 26 items divided into four subscales measuring motor performance, intellectual disturbances, and emotional impairment; the fourth subscale, entitled self-care, estimates different dementia symptoms' characteristics over time, comprising the assessment of confusion, 
Table 3 Brief overview of the selected multi-domain AD scales

\begin{tabular}{|c|c|c|c|c|c|c|}
\hline Scale & $\begin{array}{l}\text { Domains/dimensions } \\
\text { (number of items) }\end{array}$ & $\begin{array}{l}\text { Patient } \\
\text { population }\end{array}$ & Rating & Rater & $\begin{array}{l}\text { Item } \\
\text { scoring }\end{array}$ & Application \\
\hline $\begin{array}{l}\text { BGP } \\
\text { (van der } \\
\text { Kam et } \\
\text { al. 1971) }\end{array}$ & $\begin{array}{l}\text { Caregiver dependency (9), Social } \\
\text { skills (7), Aggressiveness (5), } \\
\text { Psychoorganic syndrome (11), } \\
\text { Depressiveness (3) }\end{array}$ & $\begin{array}{l}\text { Moderate } \\
\text { to severe } \\
\mathrm{AD}\end{array}$ & Observation & $\begin{array}{l}\text { Nurse, } \\
\text { Caregiver }\end{array}$ & 3-point & $\begin{array}{l}\text { Used in clinical trials for assessment of } \\
\text { behavior in psychogeriatric patients; the BGP- } \\
\text { care dependency subscale reflects cognitive } \\
\text { and functional characteristics related with } \\
\text { increased need for care }\end{array}$ \\
\hline $\begin{array}{l}\text { GBS } \\
\text { (Gottfries } \\
\text { et al. } \\
1982 \text { ) }\end{array}$ & $\begin{array}{l}\text { Intellect (11), Emotion (3), Self-care } \\
\text { (6), Behavior (6) }\end{array}$ & $\begin{array}{l}\text { Mild to } \\
\text { severe } A D\end{array}$ & $\begin{array}{l}\text { Observation/ } \\
\text { interview }\end{array}$ & $\begin{array}{l}\text { Physician, } \\
\text { Psychologist, } \\
\text { Nurse }\end{array}$ & 7-point & $\begin{array}{l}\text { Global assessment tool for evaluating } \\
\text { dementia symptoms; it is not suitable for } \\
\text { diagnostic purposes but for repeated } \\
\text { measurements of patients participating in } \\
\text { clinical trials for assessment of drug treatment } \\
\text { effects }\end{array}$ \\
\hline $\begin{array}{l}\text { NOSGER } \\
\text { (Brunner } \\
\text { \& Spiegel } \\
\text { 1990) }\end{array}$ & $\begin{array}{l}\text { Memory (5), IADL (5), Self-care (5), } \\
\text { Mood (5), Social behavior (5), } \\
\text { Disturbing behavior (5) }\end{array}$ & $\begin{array}{l}\text { Mild to } \\
\text { moderate } \\
\text { AD }\end{array}$ & Observation & $\begin{array}{l}\text { Nurse, } \\
\text { Caregiver }\end{array}$ & 5-point & $\begin{array}{l}\text { Developed for longitudinal studies in } \\
\text { psychogeriatrics; used in several European and } \\
\text { North American centers; suitable for dementia } \\
\text { screening }\end{array}$ \\
\hline $\begin{array}{l}\text { SCAG } \\
\text { (Shader } \\
\text { et al. } \\
1974 \text { ) }\end{array}$ & $\begin{array}{l}\text { Cognitive dysfunction (4), } \\
\text { Interpersonal relationship (4), } \\
\text { Apathy (4), Affect (3), Somatic } \\
\text { function (3) }\end{array}$ & $\begin{array}{l}\text { Senile } \\
\text { dementia }\end{array}$ & $\begin{array}{l}\text { Observation/ } \\
\text { interview }\end{array}$ & Clinician & 7-point & $\begin{array}{l}\text { General-purpose rating scale developed for } \\
\text { evaluation of pharmacotherapy in senile } \\
\text { dementia; widely used in drug research trials } \\
\text { during 1980's }\end{array}$ \\
\hline $\begin{array}{l}\text { VL } \\
\text { (Porzsolt } \\
\text { et al. } \\
2004 \text { ) }\end{array}$ & $\begin{array}{l}\text { Communication (15), Negative } \\
\text { affect (10), Bodily contact (5), } \\
\text { Aggression (4), Mobility (6) }\end{array}$ & Severe AD & Observation & $\begin{array}{l}\text { Physician, } \\
\text { Nurse }\end{array}$ & 7-point & $\begin{array}{l}\text { A relatively new developed proxy-rating QoL } \\
\text { instrument for documentation of the outcome } \\
\text { of geriatric inpatient rehabilitation }\end{array}$ \\
\hline
\end{tabular}

AD, Alzheimer's disease; BGP, Behavioral Rating Scale for Geriatric Patients; GBS, Gottfries-Brane-Steen; NOSGER, Nurses' Observation Scale for Geriatric Patients; SCAG, Sandoz Clinical Assessment Geriatric; VL, the Vienna List

irritability, agony, anxiety, mood, and restlessness. Only trained clinicians (physicians, psychologists and nurses) can administer it. The rating takes about 30 minutes and is based on observation of the patient during a semi-structured interview. The scale is not meant for diagnostic purposes but for repeated measurements of patients participating in clinical trials and evaluation of drug treatment effects.

The NOSGER is a rating scale that covers a wide range of behavioral pathology relevant to daily functioning and independent of gender or social status of the patients [70]. It consists of 30 items which measure impairment in the following areas: memory, IADL, basic ADL, mood, socialization, and disturbing behavior. Each item is rated on a five-point scale according to frequency of occurrence. Rating takes about 20 minutes and is based on direct observation of daily behavior by the nurse/caregiver over a two-week period. The scale was developed for rating the frequency of behavioral disturbances, but appears suitable for dementia screening as well. Validation studies have shown good acceptance of the scale, high inter-rater and test-retest reliability, and high correlations of NOSGER dimension scores with results of other scales [70].

Distinct from the first three multi-domain scales, the BGP is predominantly a scale for behavioral assessment of geriatric patients. It has been used in Europe since 1971 and has demonstrated good reliability in measuring longitudinal changes. Thirty-five items are included in the BGP, covering aspects of cognition, function, and behavior. The BGP-Care dependency subscale (nine items) is particularly used for assessment of cognitive and functional characteristics associated with increased need for care. The rating is based on observed behavior for a week by the clinical nursing staff. The scores range from 0 to 70 , higher scores reflecting increased severity.

In contrast to the BGP, the Vienna List is a relatively new instrument. It has been developed as a proxy-rating measurement for QoL in patients with severe dementia [72]. The scale consists of 40 items grouped into five factors describing behavior of demented patients. The scale has also been validated as a useful, differentiating, and practical tool for documentation of the outcome of geriatric inpatient rehabilitation [74].

Each of the identified five multi-domain scales was compared with the requirements listed in Table 1 to reveal its relevance to daily medical practice. It shows that only one of the selected scales, the GBS, is applicable to all AD severity stages (mild to severe). The SCAG can also differentiate between four groups of individuals: healthy, minimum dementia, depression, and severe dementia. However, SCAG was developed for evaluation of the most common clinical manifestations of geriatric dysfunction and is not specific to problem behaviors common among patients with AD. The NOSGER is applicable only for mild to moderate AD 
patients, whereas the BGP and the Vienna List are designed for moderate to severe and severely demented patients, respectively.

All the scales were reported as easily administrable and practical for use, requiring a relatively short time for administration. However, both the BGP and the Vienna List appear a bit lengthy (35 and 40 items, respectively). For comparison, the patient and caregiver versions of the 13-item QoL-AD scale can be completed on average in 10 minutes [59]. Two of the scales, the NOSGER and the BGP, are based on observations taken by nurse/caregiver, whereas the other three scales are based on observations by a trained clinician. Validation data (inter-rater, test-retest, construct and concurrent reliability) are published for all selected scales. Most of the scales have shown a good sensitivity to measure changes with disease progression. The SCAG and GBS have also proven their reliability in monitoring treatment effects over time.

A common disadvantage of all five scales is the emphasis given to the assessment of a single AD-symptom domain despite the scales' multi-domain structure. Particularly, the assessment of behavior is prevailing in the NOSGER, BGP, and the Vienna List, whereas the cognitive evaluation is central to the GBS and SCAG scales.

The GBS is applicable to all AD severity stages but its disadvantage is the inclusion of only basic ADL, which can lead to ceiling effects in mild AD patients. Also, no IADL are scored and QoL is not assessed. Furthermore, the GBS contains only one language item (language disturbances) while the NOSGER, BGP, and the Vienna List, which were developed on a more caregiver-based perspective, also take into account aspects related to social interaction. For example, the NOSGER contains items such as "is interested in what is going on around him/her", "helps others as far as physically able", or "when asked questions, seems quarrelsome and irritable". Unfortunately, these scales have limitations concerning the severity AD stage to which they can be applied.

\section{Development of a new multi-domain AD scale}

Despite the variety of validated AD-scales revealed by our literature survey, none of the selected instruments fulfilled all criteria for a multi-domain $\mathrm{AD}$ scale given in Table 1. The development of a new instrument that can address multiple domains at all stages of AD severity while remaining sensitive to changes and therapy effects seems to be an ambitious goal. To achieve it, the approach of combining available $\mathrm{AD}$ scales appears to be inappropriate as these scales have different designs and scopes of assessment. Hence, we believe that the new multi-domain instrument should be developed with a novel design that may best serve primary care physicians to assess severity of AD symptoms, disease progression, and therapy effects in daily medical practice. How should such a scale be created and used in practice? First of all, practice-relevant endpoints that cover a broad spectrum of AD symptoms and enable global clinical evaluation of the disease progression should be selected and included in an appropriate test-frame applicable to all disease severity stages. We believe that an external assessment carried out by a medical practitioner and based on an interview with the patient and/ or patient's caregiver would be the most appropriate format for the new practical instrument. Given the broad disease severity range of the scale, special attention should be given to eventual floor and ceiling effects, which can compromise the measurement. Ceiling effects may be expected for patients in the early AD stage; therefore, we would propose developing the scale only for assessment of patients with clearly established diagnosis of $\mathrm{AD}$ and exclude prodromal stages of dementia, such as mild cognitive impairment. Another challenge is the development of a test-frame applicable to a broad scope of AD patients differing in terms of cultural background. This may be achieved by using a scale allowing adjustments to individual patients without loosing sensitivity and reliability. An interview based on a given example of event or action, that is, scenario, for assessment of AD symptoms would be an appropriate testformat; thus, alternative scenarios could be adapted to the individual patient. Validated translations in many languages would also be required. Besides being a reliable and sensitive tool, such a scale should also be userfriendly to become often used in daily clinical practice. We assume the new scale for clinical practice should take about 15 to 30 minutes for administration by an experienced clinician, who is supposed to be familiar with the background clinical information of the patient. At following assessments, such a scale would enable the user to obtain and evaluate data faster and at ease. For accurate assessment, the clinician should use a broad source of information about the patient, for example, from a caregiver, a relative, or the patient himself. Accordingly, an informant interview would be an appropriate form of administration.

Altogether, the development of the new instrument would require considerable effort, combining the knowledge and experience of primary care clinicians, researchers, and caregivers from different countries. As a first step towards scale development, a panel meeting with medical and caregiver experts with long-term experience in $\mathrm{AD}$ therapy was organized to discuss the content of this new scale and to establish a strategy for scale development. In general, a consensus was achieved that most AD scales commonly used in clinical practice do not 
comprise all requirements for a practical multi-domain AD scale. Most are standardized assessment tools to measure predominantly the severity of major dysfunction in a particular AD domain, but are not sufficiently sensitive to all $\mathrm{AD}$ stages, therefore are not easily applicable for tracking changes in routine medical practice and comparable in different patient populations. Moreover, several aspects of cognition and communication/ social interaction, which are of great impact for daily medical practice, appear to be neglected and/or not well captured by the commonly used AD scales. Cognitive aspects such as misidentification, learning aptitude, selfdisclosure, decision making, self-determination, and disturbed/slowed response to external stimuli, seem rarely presented in the selected standard measures. The following aspects of communication and social interaction were also considered seldom presented in AD scales: responsiveness, correct use and interpretation of gestures and facial expressions, implementation of commands, cooperation in care and daily living, social involvement, adaptability, relationships with family/ friends, and intimacy of contacts (informal/formal).

The extensive discussion on these specific practical challenges contributed to the primary selection of practice-relevant assessment criteria to be included in the new scale. In total, 16 items with high clinical relevance were selected for the new instrument and grouped as follows: cognition (three items), communication (three items), behavior (five items), and activity of daily living (ADL) (three items). Two additional endpoints for global clinical evaluation of patients' quality of life and caregiver burden were considered relevant as well. As a next step, a framework appropriate for assessment of patients at all AD severity stages was developed based on stage-specific scenarios (early, middle, and late) and relevant examples for assessment of each scale item. For an individual patient, the scenario should be chosen by the clinician as dependent on the clinician's global impression of patient's AD-relevant symptoms and their severity. Such a test framework enables also the use of patient-adapted scenarios, which makes it appropriate for assessment of patients with diverse cultural, social, or educational backgrounds. Further considerations regarding test utility were discussed at the panel meetings, leading to the final set up of a clinical trial design whose primary goal was to evaluate the validity, reliability, and sensitivity of the new instrument. This clinical trial has recently been performed, demonstrating the validity and reliability of the new instrument. Some of the clinical trial results have recently been presented at the 11th International Geneva/Springfield Symposium on Advances in Alzheimer Therapy [75,76] and will be published in a separate manuscript currently in preparation.

\section{Conclusions}

Given the literature review results and extensive discussions at the expert panel meetings, a new AD scale designed for multidimensional assessment of symptoms in daily medical practice and applicable to all AD severity stages is definitely needed. Such a scale would serve experienced clinicians and researchers in monitoring patient-relevant AD symptoms over time in clinical practice, and in evaluating the efficacy of new treatments under development. A great advantage of such a rating tool for clinical practice is the possibility to easily profile AD-relevant symptoms for a patient, and thus get a broad overview of a patient's disease status and therapy effects over time. Also, such a tool may be used as a sensitive global measure of changes across severity stages, and thus provide evaluations of therapy effects in long-term assessments to caregivers or reimbursement agencies.

\section{Abbreviations}

AD: Alzheimer's disease; ADAS-Cog: Alzheimer's Disease Assessment Scale Cognitive Subscale; ADCS-ADL $19 / 23$ : Alzheimer's Disease Cooperative Study Activities of Daily Living Inventory 19- or 23-item Scale; ADL: activities of daily living; ADRQL: Alzheimer Disease Related Quality of Life; B-ADL: Bayer Activities of Daily Living Scale; BEHAVE-AD: Behavioral Pathology in Alzheimer's Disease Rating Scale; BGP: Behavioral Rating Scale for Geriatric Patients; BPRS: Brief Psychiatric Rating Scale; CGl: Clinical Global Impression; DQoL: Dementia Quality of Life Instrument; GBS: Gottfries-Brane-Steen; IADL: instrumental activities of daily living; MMSE: Mini-Mental State Examination; NOSGER: Nurses' Observation Scale for Geriatric Patients; NPI:

Neuropsychiatric Inventory; NTB: Neuropsychological Test Battery; QoL: quality of life; QoL-AD: Quality of Life-Alzheimer's Disease; QUALID: Quality of Life in Late-Stage Dementia Scale; SCAG: Sandoz Clinical Assessment Geriatric; SEIQoL-DW: Evaluation of Individual Quality of Life - Direct Weighing; SIB: Severe Impairment Battery; SIB-L: Severe Impairment Battery Language; VL: The Vienna List.

\section{Acknowledgements}

This study was supported by a grant from Merz Pharmaceuticals $\mathrm{GmbH}$, Frankfurt, Germany. We thank Dr. Ivanka Yaneva-Hoffmann who provided medical writing services on behalf of Pierrel Research Europe, Germany.

\section{Author details}

'Memory Center, CHU - University of Nice Sophia Antipolis, Hôpital de Cimiez, 4 av Victoria, 06000 Nice, France. ${ }^{2}$ Alzheimer's Disease Center, New York University Langone Medical Center, 550 First Avenue, New York, NY 10016, USA. ${ }^{3}$ Alzheimer's Disease Research Unit, McGill Center for Studies in Aging, 6825 LaSalle Boulevard, Montreal, QC, Canada. ${ }^{4}$ Department of Geriatric Psychiatry and Psychotherapy, Alexian Hospital, Oberdiessemer Str. 136, 47805 Krefeld, Germany. ${ }^{5}$ Alzheimer Disease Research Center, Karolinska Institutet, Novum 5th Floor, SE-14186 Stockholm, Sweden. ${ }^{6}$ Merz

Pharmaceuticals, Eckenheimer Landstr. 100, 60318 Frankfurt am Main, Germany.

\section{Authors' contributions}

All of the authors contributed to the study conception and selection of criteria for the design of a new assessment instrument. FT coordinated the literature survey and drafted the manuscript. PR, RI, SG, SF and BW provided critical remarks on drafts and guided the manuscript through its development. All authors read and approved the final manuscript.

\section{Competing interests}

PR, SF, SG, RI, and BW are members of an Advisory Board for Alzheimer's disease coordinated from Pierrel Research Europe (Essen, Germany), for 
which they received an honorarium from Merz Pharmaceuticals (Frankfurt, Germany). FT is an employee of Merz Pharmaceuticals and receives a fixed salary. SG, RI, BW and PR are also members of the Advisory Board at Lundbeck, in which capacity they have received consulting fees. In the last five years, PR has received honoraria or royalties from Eisai, Wyeth, Novartis, Janssen, and GE Healthcare. RI has received consultant fees from APK, Austroplant, BDI, Beltz Test, BOD, Caritas Siegen, Double Helix Development, Eisai, Friedrichverlag, GE Healthcare, Hogrefe, IFE, Janssen, KDA, Landesinitiative Demenz Service NRW, LVR Düren, Medical Tribune, Med. Komm., Novartis, Pfizer, Pfrimmer Nutritia, Pierrel, Schwabe, Thieme, Urban \& Vogel, and Westermayer.

Received: 14 December 2009 Accepted: 26 August 2010

Published: 26 August 2010

\section{References}

1. Khachaturian ZS, Radebaugh TS, (Eds): Alzheimer's Disease: Cause(s), Diagnosis, Treatment, and Care Boca Raton, FL: CRC Press 1996.

2. Geldmacher DS: Treatment guidelines for Alzheimer's disease: redefining perceptions in primary care. Prim Care Companion I Clin Psychiatry 2007, 9:113-121.

3. Schmitt FA, Wichems $\mathrm{CH}$ : A systematic review of assessment and treatment of moderate to severe Alzheimer's disease. Prim Care Companion J Clin Psychiatry 2006, 8:158-169.

4. Lawton MP: A multidimensional view of quality of life. In The Concept and Measurement of Quality of Life in the Frail Elderly. Edited by: Barren JE, Lubben JE, Rowe JC, Deutschman DE. New York: Academic Press; 1991:3-27.

5. Guideline on medicinal products for the treatment of Alzheimer's disease and other dementias (CPMP/EWP/553/95 Rev.1). [http://www. emea.europa.eu].

6. Saxton J, Swihart AA: Neuropsychological assessment of the severely impaired elderly patient. Clin Geriatr Med 1989, 5:531-543.

7. Livingston G, Katona C, François C, Guilaume C, Cochran J, Sapin C: Characteristics and health status change over 6 months in people with moderately severe to severe Alzheimer's disease in the U.K. Int Psychogeriatr 2006, 18:527-538.

8. Black R, Greenberg B, Ryan JM, Posner H, Seeburger J, Amatniek J Resnick M, Mohs R, Miller DS, Saumier D, Carrillo MC, Stern Y: Scales as outcome measures for Alzheimer's disease. Alzheimers Dement 2009, 5:324-339.

9. Folstein MF, Folstein SE, McHugh PR: Mini-Mental State: a practical method for grading the cognitive state of patients for the clinician. $J$ Psychiatr Res 1975, 12:189-198.

10. Tombaugh TN, Mclntyre NJ: The mini-mental state examination: a comprehensive review. J Am Geriatr Soc 1992, 40:922-935.

11. Clark CM, Sheppard L, Fillenbaum GG, Galasko D, Morris JC, Koss E, Mohs R, Heyman A: Variability in annual Mini-Mental State score in patients with probable Alzheimer's disease: A clinical perspective of data from CERAD. Arch Neurol 1999, 56:857-962.

12. Hensel A, Angermeyer MC, Riedel-Heller SG: Measuring cognitive change in older adults: reliable change indices for the mini-mental state examination. J Neurol Neurosurg Psychiatry 2007, 78:1298-1303.

13. Reisberg B: Global measures: utility in defining and measuring treatment response in dementia. Int Psychogeriatr 2007, 19:421-456.

14. Rosen WG, Mohs RC, Davis KL: A new rating scale for Alzheimer's disease. Am J Psychiatry 1984, 141:1356-1364.

15. Doraiswamy MP, Kaiser L, Bieber F, Garman RL: The Alzheimer's disease assessment scale: Evaluation of psychometric properties and patterns of cognitive decline in multicenter clinical trials of mild to moderate Alzheimer's disease. Alzheimer Dis Assoc Disord 2001, 15:174-183.

16. Mohs RC, Knopman D, Petersen RC, Ferris SH, Ernesto C, Grundman M, Sano M, Bieliauskas L, Geldmacher D, Clark C, Thal L: Development of cognitive instruments for use in clinical trials of antidementia drugs: additions to the Alzheimer's Disease Assessment scale that broaden its scope. Alzheimer Dis Assoc Disord 1997, 11 Suppl 2:S13-S21.

17. Harrison J, Minassian SL, Jenkins L, Black RS, Koller M, Grundman M: A neuropsychological test battery for use in Alzheimer disease clinical trials. Arch Neurol 2007, 64:1323-1329.

18. Saxton J, Swihart AA, McGonigle-Gibson KL, Miller VJ, Boller F: Assessment of the severely impaired patient: description and validation of a new neuropsychological test battery. Psychol Assess 1990, 2:298-303.
19. Saxton J, Kastango KB, Hugonot-Diener L, Boller F, Verny M, Sarles CE, Girgis RR, Devouche E, Mecocci P, Pollock BG, DeKosky ST: Development of a short form of the Severe Impairment Battery. Am J Geriatr Psychiatry 2005, 13:999-1005.

20. Ferris $S$, Ihl R, Robert $P$, Winblad B, Gatz G, Tennigkeit F, Gauthier S: Severe Impairment Battery Language Scale, a language assessment tool for Alzheimer's disease patients. Alzheimer's Dement 2009, 5:375-379.

21. Peavy GM, Salmon DP, Rice VA, Galasko D, Samuel W, Taylor Kl, Ernesto C, Butters N, Thal L: Neuropsychological assessment of severely demented elderly: the severe cognitive impairment profile. Arch Neurol 1996, 53:367-372.

22. Erzigkeit $\mathrm{H}$ : The SKT: a short cognitive performance test as an instrument for the assessment of clinical efficacy of cognition enhancers. In Diagnosis and Treatment of Senile Dementia. Edited by: Bergener M, Reisberg B. Berlin: Springer-Verlag; 1989:167-174.

23. Katz $S$, Ford $A B$, Moskowitz RW, Jackson BA, Jaffe MW: Studies of illness in the aged. The Index of ADL: a standardized measure of biological and psychosocial function. JAMA 1963, 185:914-919.

24. Lawton MP, Brody EM: Assessment of older people: self-maintaining and instrumental activities of daily living. Gerontologist 1969, 9:179-186.

25. Galasko D, Bennet D, Sano M, Ernesto C, Thomas R, Grundman M, Ferris S: An inventory to assess activities of daily living for clinical trials in Alzheimer's disease. The Alzheimer's Disease Cooperative Study. Alzheimer Dis Assoc Disord 1997, 11:s33-39.

26. Gélinas I, Gauthier L, McIntyre M, Gauthier S: Development of a functional measure for persons with Alzheimer's disease: The disability assessment for dementia. Am J Occup Ther 1999, 53:471-481.

27. Teunisse S, Derix MM: Measurement of activities of daily living in patients with dementia living at home: development of a questionnaire. Tijdschr Gerontol Geriatr 1991, 22:53-59.

28. Hébert $R$, Guilbault J, Desrosiers J, Dubuc N: The functional autonomy measurement system (SMAF): A clinical-based instrument for measuring disabilities and handicaps in older people. Geriatrics Today: I Can Geriatr Soc 2001, 4:141-147.

29. Linn MW: A rapid disability rating scale. J Am Geriatr Soc 1967, 15:211-214.

30. Hindmarch I, Lehfeld $H$, Jongh P, Erzigkeit $H$ : The Bayer Activities of Daily Living Scale (B-ADL). Dement Geriatr Cogn Disord 1998, 9:20-26.

31. Galasko D, Bennet D, Sano M, Marson D, Kaye J, Edland SD: Alzheimer's Disease cooperative Study. ADCS Prevention Instrument Project: assessment of instrumental activities of daily living for communitydwelling elderly individuals in dementia prevention clinical trials. Alzheimer Dis Assoc Disord 2006, 20:s152-169.

32. Pfeffer R, Kurosaki C, Harrah J, Chance S, Filos S: Measurement of functional activities of daily living of older adults in the community. $J$ Gerontol 1982, 37:323-329.

33. Sikkes SAM, de Lange-de Klerk ESM, Pijnenburg YAL, Scheltens $P$, Uitdehaag BMJ: A systematic review of instrumental activities of daily living scales in dementia: room for improvement. J Neurol Neurosurg Psychiatry 2009, 80:7.

34. Guy W: Clinical Global Impression Scale. ECDEU Assessment Manual for Psychopharmacology - Revised (DHEW Publ No ADM 76-338) Rockville, MD: Department of Health, Education, and Welfare, Public Health Service, Alcohol, Drug Abuse, and Mental Health Administration, NIMH, Psychopharmacology Research Branch, Division of Extramural Research Programs 1976, 218-222.

35. Hughes $C P$, Berg L, Danziger WL, Coben LA, Martin RL: A new clinical scale for the staging of dementia. Br J Psychiatry 1982, 140:566-572.

36. Reisberg B, Ferris SH, de Leon MJ, Crook T: The Global Deterioration Scale for assessment of primary degenerative dementia. Am J Psychiatry 1982, 139:1136-1139.

37. Reisberg B: Functional assessment staging (FAST). Psychopharmacol Bull 1988, 24:653-659.

38. Schneider LS, Olin JT, Doody RS, Clark CM, Morris JC, Reisberg B, Schmitt FA, Grundman M, Thomas RG, Ferris SH: The Alzheimer's Disease Cooperative Study. Validity and reliability of the Alzheimer's Disease Cooperative Study - Clinical Global Impression of Change. Alzheimer Dis Assoc Disord 1997, 11:22-32.

39. Reisberg B, Ferris SH: Clinician's interview-based impression of changeplus. In Guide to Assessment Scales in Dementia. Edited by: Kelly C, NewtonHowes G. London: Science Press; 1994:. 
40. Reisberg B, Borenstein J, Salob SP, Ferris SH, Franssen E, Georgotas A: Behavioral symptoms in Alzheimer's disease: phenomenology and treatment. J Clin Psychiatry 1987, 48:9-15.

41. Overall JE, Gorham DR: The brief psychiatric rating scale. Psycholog Rep 1962, 10:799-812.

42. Cummings JL, Mega M, Gray K, Rosenberg-Thompson S, Carusi DA, Gornbein J: The Neuropsychiatric Inventory: comprehensive assessment of psychopathology in dementia. Neurology 1994, 44:2308-2314.

43. Kaufer DI, Cummings JL, Ketchel P, Smith V, MacMillan A, Shelley T, Lopez OL, DeKosky ST: Validation of the NPI-Q, a brief clinical form of the Neuropsychiatric Inventory. J Neuropsychiatry Clin Neurosci 2000, 12:233-239.

44. Connor DJ, Sabbagh MN, Cummings UL: Comment on administration and scoring of the Neuropsychiatric Inventory in clinical trials. Alzheimers Dement 2008, 4:390-394.

45. Tariot PN, Mack JL, Patterson MB, Edland SD, Weiner MF, Fillenbaum G, Blazina L, Teri L, Rubin E, Mortimer YA, et al: The Behavior Rating Scale for Dementia of the Consortium to Establish a Registry for Alzheimer's Disease. The Behavioral Pathology Committee of the Consortium to Establish a Registry for Alzheimer's Disease. Am J Psychiatry 1995, 152:1349-1357

46. Baumgarten $M$, Becker $R$, Gauthier S: Validity and reliability of the dementia behavior disturbance scale. J Am Geriatr Soc 1990, 38:221-226.

47. Cohen-Mansfield J: Agitated behaviors in elderly. Preliminary results in the cognitively deteriorated. J Am Geriatr Soc 1986, 34:722-727.

48. Yesavage JA, Brink TL, Rose TL, Lum O, Huang V, Adey M, Leirer VO: Development and validation of a geriatric depression screening scale: a preliminary report. J Psychiatr Res 1982-1983, 17:37-49.

49. Robert PH, Clairet S, Benoit M, Koutaich J, Bertogliati C, Tible O, Caci H, Borg $M$, Brocker $P$, Bedoucha $P$ : The apathy inventory: assessment of apathy and awareness in Alzheimer's disease, Parkinson's disease and mild cognitive impairment. Int J Geriatr Psychiatry 2002, 17:1099-1105.

50. Sunderland T, Alterman IS, Yount D, Hill JL, Tariot PN, Newhouse PA, Mueller EA, Mellow AM, Cohen RM: A new scale for assessment of depressed mood in dementia patients. Am J Psychiatry 1988, 145:955-959.

51. Alexopoulos GS, Abrams RC, Young RC, Shamoian CA: Cornell scale for depression in dementia. Biol Psychiatry 1988, 23:271-284

52. Tappen RM, Williams C: Alzheimer's Mood Scale: Validity and reliability [abstract]. Gerontolog Soc Am, 52nd Ann Sci Meeting, San Francisco 1999.

53. Ready RE, Ott BR: Quality of life measures for dementia. Health Qual Life Outcomes 2003, 1:11.

54. Lawton MP: Quality of life in Alzheimer disease. Alzheimer Dis Assoc Disord 1994, 8:138-150.

55. Sands L, Ferriera P, Stewart A, Brod M, Yaffe K: What explains differences between dementa patients' and their caregivers' ratings of patients' quality of life? Am J Geriatr Psychiatry 2004, 12:272-280.

56. Rockwood K, Graham JE, Fay S, ACADIE Investigators: Goal setting and attainment in Alzheimer's disease patients treated with donepezil. J Neurol Neurosurg Psychiatry 2002, 73:500-507.

57. Rabins PV, Kasper JD, Kleinman L, Black BS, Patrick DL: Concepts and methods in the development of the ADRQL: An instrument for assessing health-related quality of life in persons with Alzheimer's disease. J Ment Health Aging 1999, 15:33-48.

58. Brod M, Stewart AL, Sands L, Walton P: Conceptualization and measurement of quality of life in dementia: The dementia quality of life instrument (DQoL). Gerontologist 1999, 39:25-35.

59. Logsdon RG, Gibbons LE, McCurry SM, Teri L: Quality of life in Alzheimer's Disease: patient and caregiver reports. Psychosom Med 1999, 64:510-519.

60. Logsdon RG, Gibbons LE, McCurry SM, Teri L: Assessing the quality of life in older adults with cognitive impairment. Psychosom Med 2002, 64:510-519.

61. Weiner MF, Martin-Cook K, Svetlik DA, Saine K, Foster B, Fontaine CS: The quality of life in late-stage dementia (QUALID) scale. J Am Med Dir Assoc 2000, 1:114-116.

62. DeJong R, Osterlund OW, Roy GW: Measurement of quality of life changes in patients with Alzheimer's disease. Clinical Therapeutics 1989, 11:545-554.

63. Moons P, Marquet K, Budts W, De Geest S: Validity, reliability and responsiveness of the Schedule for the Evaluation of Individual Quality of Life-Direct Weighting (SEIQoL-DW) in congenital heart disease. Health Qual Life Outcomes 2004, 2:27.
64. Hurley AC, Volicer BJ, Hanrahan PA, Houde S, Volicer L: Assessment of discomfort in advanced Alzheimer patients. Res Nurs Health 1992, 15:369-377.

65. Savundranayagam MY, Hummert ML, Montgomery RJV: Investigating the effects of communication problem on caregiver burden. J Gerontol B Psychol Sci Soc Sci 2005, 60B:s48-55.

66. Powell JA, Hale MA, Bayer AJ: Symptoms of communication breakdown in dementia: Carers' perception. Eur J Disord Commun 1995, 30:65-75.

67. Shader RI, Harmaz JS, Salzman C: A new scale for clinical assessment in geriatric populations: Sandoz Clinical Assessment - Geriatric (SCAG). J AM Geriatr Soc 1974, 22:107-103.

68. Gottfries CG, Bråne G, Gullberg B, Steen G: A new rating scale for dementia syndromes. Arch Gerontol Geriatr 1982, 1:311-330.

69. Bråne G, Gottfries CG, Winblad B: The Gottfries-Bråne-Steen scale: validity, reliability and application in anti-dementia drug trials. Dement Geriatr Cogn Disord 2001, 12:1-14.

70. Brunner C, Spiegel R: Eine Validierungsstudie mit der NOSGER, einem neuen Beurteilungsinstrument für die Psychogeriatrie. Zeitschrift für klinische Psychologie 1990, 19:211-229.

71. van der Kam P, Mol F, Wimmers M: Beoordelingsschaal voor Oudere Patienten (BOP) Deventer, the Netherlands: Van Loghum Slaterus 1971

72. Porzsolt F, Kojer M, Schmidl M, Greimel ER, Sigle J, Richter J, Eisemann M: A new instrument to describe indicators of well-being in old-old patients with severe dementia - The Vienna List. Health Qual Life Outcomes 2004, 2:10.

73. Venn RD: The Sandoz Clinical Assessment Geriatric (SCAG) scale. A general purpose psychiatric rating scale. Gerontology 1983, 29:185-198

74. Richter J, Schwarz M, Eisemann M, Bauer B: Validation of the "Vienna List" as a proxy measure of quality of life. Qual Life Res 2004, 13:1725-1735.

75. Gauthier S, Ihl R, Robert P, Winblad B, Ferris B, Tennigkeit F: Development of the Relevant Outcome Scale for Alzheimer's Disease (ROSA), a multidomain assessment for daily medical practice. Abstracts from the 11th International Geneva/Springfield Symposium on Advances in Alzheimer Therapy: Neurobiol Aging 2010, 31(Suppl 1).

76. Ferris S, Ihl R, Robert P, Winblad B, Gauthier S, Holthoff V, Sternberg K, Tennigkeit F: Validation of the Relevant Outcome Scale for Alzheimer's disease (ROSA): a new instrument for daily medical practice. Abstracts from the 11th International Geneva/Springfield Symposium on Advances in Alzheimer Therapy: Neurobiol Aging 2010, 31(Suppl 1).

77. Blessed $\mathrm{G}$, Tomlinson BE, Roth M: The association between quantitative measures of dementia and of senile change in the cerebral grey matter of elderly subjects. Br J Psychiatry 1968, 114:797-811.

78. Grevett C, O'Brien J: A new database for CAMCOG. Old Age Psychiatrist 2002, 28:9

79. Mattis S: Mental status examination for organic mental syndrome in the elderly patient. In Geriatric Psychiatry: A Handbook for Psychiatrics and Primary Care Physicians. Edited by: Bellar L, Karasu T. New York: Grune and Stratton; 1976:77-101

80. Johnson N, Barion A, Rademaker A, Rehkemper G, Weintraub S: The Activities of Daily Living Questionnaire: A validation study in patients with dementia. Alzheimer Dis Assoc Disord 2004, 18:223-230.

81. Bucks RS, Ashworth DL, Wilcock GK, Siegfried K: Assessment of activities of daily living in dementia: Development of the Bristol activities of daily living scale. Age and Ageing 1996, 25:113-120.

82. Bellelli G, Frisoni GB, Bianchetti A, Trabucchi M: The Bedford Alzheimer nursing deverity scale for the severely demented: validation study. Alzheimer Dis Assoc Disord 1997, 11:71-77.

83. Mahoney Fl, Barthel DW: Functional evaluation: The Barthel Index. Md State Med J 1965, 14:61-65.

84. Schwartz GE: Development and validation of geriatric evaluation by relatives rating instrument (GERRI). Psychological Reports 1983, 53:479-488.

85. Wilkinson IM, Graham-White J: Psychogeriatric dependency rating scale (PGDRS): a method of assessment for use by nurses. Br J Psychiatry 1980, 137:558-565

86. Weintraub S: The record of independent living. An informant-completed measure of activities of daily living and behavior with cognitive impairment. Am J Alzheimer's Disease \& Other Dementias 1986, 1:35-39.

87. Knopman DS, Knapp MJ, Gracon SI, Davis CS: The Clinician InterviewBased Impression (CIBI): A clinician's global change rating scale in Alzheimer's disease. Neurology 1994, 44:2315-2321. 
88. Cole MG, Dastoor DP, Koszycki D: The hierarchic dementia scale. J Clin Exp Gerontol 1983, 5:219-234.

89. Sihna D, Zemlan FP, Nelson S, Bienenfeld D, Thienhaus O, Ramaswamy G, Hamilton S: A new scale for assessing behavioral agitation in dementia. Psychiatry Res 1992, 41:73-88.

90. Burns A, Beevor A, Lelliott P, Wing J, Blakey A, Orrell M, Mulinga J, Hadden S: Health of the nation outcome scales for elderly people (HoNOS 65+). Br J Psychiatry 1999, 174:424-427.

91. Sultzer DL, Berisford MA, Gunay I: The neurobehavioral rating scale: reliability in patients with dementia. J Psychiatr Res 1995, 29:185-191

92. Teri L, Truax P, Logsdon R: Assessment of behavioral problems in dementia: The revised memory and behavior problems checklist. Psychol Aging 1992, 7:622-631.

93. Lawton MP, van Haitsma K, Perkinson M, Ruckdeschel K: Observed affect and quality of life in dementia: Further affirmations and problems. J Mental Health Aging 1999, 5:69-81.

94. Bayles KA, Tomoeda CK, Trosset MW: Relation of linguistic communication abilities of Alzheimer's patients to stage of disease. Brain and Lanquage 1992, 42:454-472.

95. Shimokawa A, Yatomi N, Anamizu S, Ashikari I, Kohno M, Maki Y, Torii S, Isono H, Sugai Y, Koyama N, Matsuno Y: Comprehension of emotions: comparison between Alzheimer type and vascular type dementias. Dement Geriatr Cogn Dis 2000, 11:268-274.

96. Helmes E, Csapo KG, Short JA: Standardization and validation of the multidimensional observation scale for elderly subjects (MOSES). J Gerontol 1987, 42:395-405.

97. Mozaz M, Rothi LJG, Anderson JM, Crucian GP, Heilman KM: Postural knowledge of transitive pantomimes and intransitive gestures. J Int Neuropsychol Soc 2002, 8:958-962.

98. Reilly MC: Development and testing of a new outcome measure of relationship between patients with Alzheimer's disease and their partners. Am J Alzheimers Dis Other Demen 2006, 21:249-257.

99. Zigler E, Phillips L: Social competence and outcome in psychiatric disorder. J Abnorm Soc Psychology 1961, 63:264-271.

doi:10.1186/alzrt48

Cite this article as: Robert et al: Review of Alzheimer's disease scales: is there a need for a new multi-domain scale for therapy evaluation in medical practice?. Alzheimer's Research \& Therapy 2010 2:24.

\section{Submit your next manuscript to BioMed Central} and take full advantage of:

- Convenient online submission

- Thorough peer review

- No space constraints or color figure charges

- Immediate publication on acceptance

- Inclusion in PubMed, CAS, Scopus and Google Scholar

- Research which is freely available for redistribution

Submit your manuscript at www.biomedcentral.com/submit 